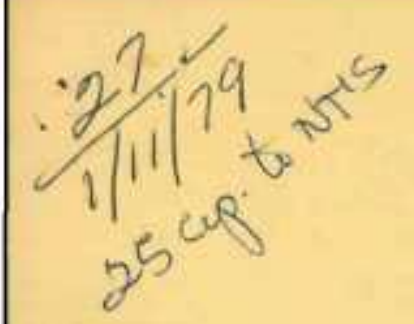

MASTER

BDX-613-2062 (Rev.)

COATING LAMINATED SUBSTRATES

By G. J. Hale

Published January 1979

Final Report

Prepared for the United States Department of Energy Under Contract Number DE-AC04-76-DP00613.

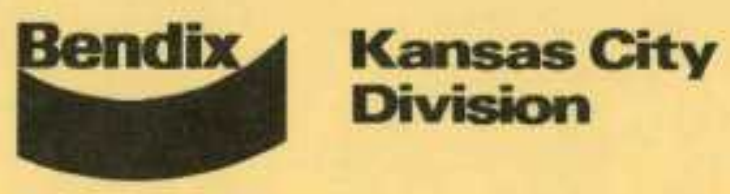




\section{DISCLAIMER}

This report was prepared as an account of work sponsored by an agency of the United States Government. Neither the United States Government nor any agency Thereot, nor any of their employees, makes any warranty, express or implied, or assumes any legal liability or responsibility for the accuracy, completeness, or usefulness of any information, apparatus, product, or process disclosed, or represents that its use would not infringe privately owned rights. Reference herein to any specific commercial product, process, or service by trade name, trademark, manufacturer, or otherwise does not necessarily constitute or imply its endorsement, recommendation, or favoring by the United States Government or any agency thereof. The views and opinions of authors expressed herein do not necessarlly state or reflect those of the United States Government or any agency thereof. 


\section{DISCLAIMER}

Portions of this document may be illegible in electronic image products. Images are produced from the best available original document. 
This report was prepared as an account of work sponsored by the United States Government. Neither the United States nor the United States Department of Energy, nor any of their employees, nor any of their contractors, subcontractors, or their employees, makes any warranty, express or implied, or assumes any legal liability or responsibility for the accuracy, completeness or usefulness of any information, apparatus, product or process disclosed, or represents that its use would not infringe privately owned rights.

Printed in the United States of America

Available From the National Technical Information Service, U.S. Department of Commerce, 5285 Port Royal Road, Springfield, Virginia 2.2161.

Price: Microfiche $\$ 3.00$

Paper Copy $\$ 4.00$ 
COATING LAMINATED SUBSTRATES

By G. J. Hale

Published January 1979 ;

Final Report

G. J. Hale, Project Leader

Project Team:

J. W. Chesney

F. A. Clay

R. V. Heckman

R. J. Russe11

D. M. Sherman

P. E. Smith

C. J. Stimetz 


\title{
COATING LAMINATED SUBSTRATES
}

\author{
BDX-613-2062 (Rev.), Final Report, Published January 1979 \\ Prepared by G. J. Hale
}

This report, covering a 4-year project, summarizes the feasibility and developinent results for coating uniform 6.3 to 12.7 m metal films on flat and non-planar Mylar or Kapton laminated substrates. Four coating techniques (ion plating of aluminum, chemical vapor deposition of aluminum, electroless plating of copper and nickel, and physical vapor deposition of aluminum and aluminum-0.12 weight percent copper) were evaluated. Based on the capability of each process and the resulting properties and structure of these coatings with respect to the requirements, physical vapor deposition was selected for further development. Processes were developed for depositing aluminum-0.12 weight percent copper alloy from an $r f$ induction vapor source and for depositing pure aluminum from an electron beam gun vapor source. In addition, precision pattern deposition of aluminum from an electron beam gun vapor source was demonstrated for flat Rapton laminated substrates.

\section{WPC-TR2/E}

This raport wis prepared at en ecoount of wook aponeorod by the Uniled Stwen Covernment. Nehher the United Stutes, nor ith

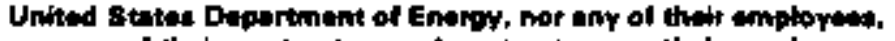

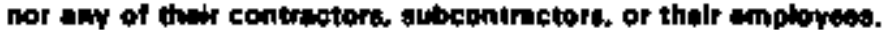

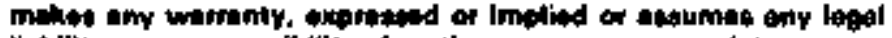

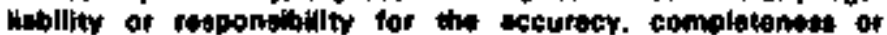

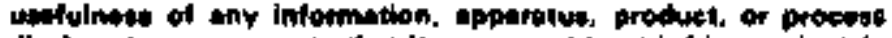

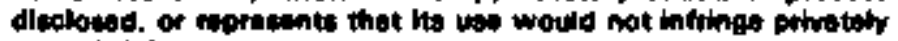
onchid ningte.
The Bendix Corporation Kansas City Division P. O. Box 1159

Kansas City. Misoouri 64141

A prime contractor with the Unitad Statse Deporimant of Entrey under Contrect Number De-AC04-76-DPOOS13 
CONTENTS

Section

SUMMARY. . . . . , . . . . . . . . . . . . .

DISCUSSION . . . . . . . . . . . . . . . . . .

SCOPE AND PURPOSE, . . . . . . . . . . . . . .

ACTIVITY . . . . . . . . . . . . . . .

Evaluation of Coating Techniques . . . . . . . . .

Physical Vapor Deposition Development. . . . . . . .

ACCOMPLISHMENTS. . . . . . . . . . . . . . . . . .

FUTURE WORK. . . . . . . . . . . . . . . . . . .

REFERENCES . . . . . . . . . . . . . . . . .

DISTRIBUTION . . . . . . . . . . . . . . . . . .
Page

4

6

6

6

6

8.

11

12

14

15

3 


\section{SUMMARY}

This activity involved evaluating four coating techniques and then developing the sclected technique, physical vapor deposition, for a specific application.

Ion plating, a vacuum metallization process; chemical vapor deposition, a chemical-thermoreactive process; electroless plating, a hydrous solution plating process; and physical vapor deposition, a vacuum deposition process, were evaluated during the first year of this 4-year project. Physical vapor deposition was selected because of its ability to produce uniform deposits with repeatable material characteristics, acceptable substrate deposition tempera* ture, and compliance to specifications.

Two physical vapor deposition processes were established for aluminum and aluminum-0.12 weight percent copper deposits. The associated equipment, process parameters, and resulting deposits were characterized. This activity included evaluating the effects of deposition rate, substrate temperature, residual gas analysis of deposition chambers during vacuum heat treatment of the substrates and prior to and during deposition, vapor source to substrate geometric configurations, and respective vapor sources, in order to optimize both vacuum systems and associated parameters to provide repeatable coating material properties. Measured film properties included: total thickness, thickness uniformity (defined as standard deviation/average thickness) across various sized non-planar substrates, film density, microstructure, electrical resistivity, specular and total reflectivity, preferred orientation, and adhesion to the laminated polyimide substrates.

Resulting data indicate that the thickness uniformity of the pure aluminum and aluminum-0.12 weight percent copper alloy films was less than 2 percent for various sized, non-planar substrates. Thickness repeatability was greater than 90 percent. Room temperature electrical resistivities for these aluminum and aluminum-0.12 weight percent copper alloy films were $2.85 \mu \Omega-\mathrm{cm}$ or less and $3.0 \mu \Omega-c m$ or less, respectively, which are very close to the bulk pure aluminum value of $2.71 \mathrm{\mu} \Omega-\mathrm{cm}$. The optically smooth and shiny surfaces were analyzed using an integrating sphere reflectometer to determine the total and specular reflectance of the films.

The electron beam gun process yielded pure aluminum films whose surfaces had a total reflectance of 90 percent with 80 to 90 percent of the reflected light specularly reflected. The rf induction process resulted in aluminum-0.12 weight percent copper films whose surfaces had a total reflectance of 84 percent with 87 percent of the reflected light specularly reflected. The density of both these deposited films exceeded 99 percent of theoretical and had 
a preferred crystal orientation of (111). The grain size was typically in the range of 0.5 to $1.0 \mu \mathrm{m}$ and electron microprobe analysis of the aluminum-0.12 weight percent copper showed the copper to be consistently distributed throughout the film. Adhesion of the deposited films to the Kapton substrate exceeded that required for post-deposttion operations and handling.

Investigation of precision pattern deposition of aluminum on polyimide substrates from an electron beam gun vapor source in a high vacuum system was conducted using bimetallic masks. The results of this investigation showed that well defined patterns can be deposited with edge tapers of approximately $45^{\circ}$. Intimate contact of the mask to the substrate must be maintained to assure consistent results. Because the bimetallic masks used for pattern deposition are easy to damage, special handling and storage would be required to provide consistent patterns. 


\section{DISCUSSION}

SCOPE AND PURPOSE

This is a final report of a 4-year project to establish and develop a plating technique capable of depositing 6.3 to $12.7 \mathrm{\mu m}$ of aluminum or other selected metals with less than 2 percent thickness uniformity (standard deviation/average thickness) on non-metaljic substrates.

The activity was initially directed towards the evaluation of various plating techniques. These techniques were ion plating, chemical vapor deposition, electroless copper plating, and physical vapor deposition. After evaluation, the most applicable technique, physical vapor deposition, was selected for development and the resultant deposits, associated processes, and equipment were characterized.

\section{ACTIVITY}

\section{Evaluation of Coating Techniques}

Selection of a viable plating technique involved the initial evaluation of ion plating of aluminum, chemical vapor deposition of aluminum, electroless plating of copper and nickel, and physical vapor deposition of aluminum and aluminum-copper alloys. Using the selected technique of physical vapor deposition (PVD), full development began with emphasis on thickness repeatability and uniformity (standard deviation/average thickness) of the deposit, on repeatable deposit characteristics, and on establishing a vacuun metallization technique for depositing directly on a Mylar or Rapton laminate substrate. During the PVD development project, a polyimide, Kapton, was selected by LLL as the prime substrate material.

\section{Ion Plating}

Ion plating was the first technique evaluated for vacuun depositing $12.7 \mu$ aluminum films on non-planar Mylar laminate substrates. Ion plating is a high vacuum evaporative deposition technique utilizing a radio frequency induction vapor source and high voltage biasing of the substrate to enhance the uniformity of the deposit for a stationary substrate. Successes with this technique included achieving full thickness values of $12.7 \mu \mathrm{m}$ with thickness uniformities of less than 3 percent. However, only one substrate could be deposited at a time and general processing was difficult. Thickness repeatability from run-to-run was dependent on a deposition power-time relationship, which did not lend itself well to 
expected process requirements for a production environment. Consequently, further activity on this deposition technique was terminated.

\section{Chemical Vapor Deposition}

The chemical vapor deposition (CVD) of aluminum (TIBAL) was evaluated next. Technical details of this deposition technique have been reported previously for other development activities.1 In general, enviconment and temperature requirements for this process would not allow deposition directly on the polyimide laminate material. Instead, the $12.7 \mathrm{\mu m}$ aluninum film would be deposited on a mandrel and transferred to the non-planar polyimide laminate. To achieve 2 percent thickress uniformity, the mandrel for the CVD deposit would have to be maintained at a uniform surface temperature of $260 \pm 2.6^{\circ} \mathrm{C}$. Initial attempts to set up the CVD system were not successful in meeting the requirements of the desired coatings. Since extensive efforts were envisioned to develop techniques for fabricating free-standing aluminum films with consistent repeatability of thickness and thickness uniformity, removing films fron mandrel, and bonding them to a non-planar polyimide substrate, evaluation of another coating technique was initiated.

Electroless Plating

Electroless coating of nickel and copper from five electroless plating solutions were evaluated for Mylar and Kapton. It was found and reported ${ }^{2}$ that the coatings from these five solutions could be continuously and adherently deposited on non-planar polyimide substrates. However, the total thickness of these coatings were limited to $2.3 \mu \mathrm{m}$ or less. To obtain thicknesses greater than $2.3 \mathrm{\mu m}$, subsequent electrolytic deposition of copper had to be used. A scanning electron microscope (SEM) analysis of

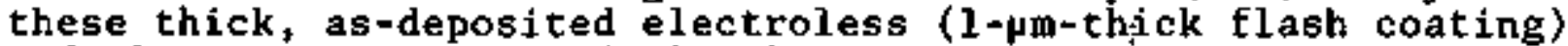
and electrolytic coated (>13 $\mu \mathrm{m})$ samples indicated that adhesion needed improvement.

Four different polyimide etchants were investigated prior to electroless coating to determine if its adhesion to the polyimide could be improved. Results of these tests indicated that tetramethylammonium hydroxide (20 weight percent) in methanol was the most promising candidate. With a SEM analysis of these etched polyimide surfaces, a quantitative point count of areal features of the etched surfaces was successfully correlated to resultant adhesive properties of the electroless coatings.

This activity was discontinued because of the thickness limitation of the more uniform electroless copper, the expected thickress non-uniformity, and observed marginal adhesion of the combined 
electroless and electrolytic copper on full size non-planar substrates.

\section{Physical Vapor Deposition}

Physical vapor deposition was the fourth technique evaluated to acquire metal deposit thicknesses of $12.7 \mu \mathrm{m}$ and thickness uniformities of less than 2 percent on various non-planar laminated polyimide substrates. This technique uses a vapor source containing the desired metal for deposition located in a high vacuum chamber. The vapor source temperature is raised until the metal vaporizes. The substrates are positioned and rotated to acquire the best thickness uniformity. Results of the initial activity were very encouraging. Desired metal deposit thicknesses and thickness uniformities were achieved. Repeatability of the general process and deposit material characteristics were well within the desired application requirements. When these results were compared to results obtained from techniques described previously, physical vapor deposition was selected for further development.

\section{Physical Vapor Deposition Development}

Physical vapor deposition (PVD) developsent was initiated using the $\mathrm{rf}$ induction vapor source, high vacuum equipment that had been initially used for the ion plating feasibility evaluation. Prior to initiating this PVD evaluation, extensive modification was required to convert this system from the ion plating mode to a thermal evaporation system. During this development period, several vapor source and fixturing modifications were required to achieve run-to-run and part-to-part consistency, and to determine the limits of this developed deposition system. This vacuum deposition system was utilized extensively for optimizing the PVD process as well as supporting other related process developments, such as substrate forming-bonding, substrate cleaning, coating thickness measurement, deposit etching, and photo fabrication. Because all these activities were interrelated, concurrent development was required to allow development of the entire product. In addition, this rf induction vacuum deposition system supplied aluminum-0.12 weight percent copper alloy coated laminates for numerous reimbursable orders from Lawrence Livermore Laboratories and Los Alamos Scientific Laboratories.

After selection of the PVD technique, a second vacuum deposition system was specified and purchased. This system was designed to have vacuum equipment and control features that represented the current state of art in vacuum technology. In addition, it was intended that this vacuum deposition system be delegated for complete material, process, and equipment characterization for future production use. This vacuum system included a commerciallyavailable electron beam gun source with an automatic deposition 
rate and thickness control. This systejn's vapor source provided a lower substrate temperature during deposition than the $r f$ induction vapor source and was more conducive for coating the laminated plastic substrates. The planetary fixtures and in-vacuum chamber bake-out capability provided a versatile system to develop optimum deposition parameters. In addition, this system provided the higher process reliability and vacuum integrity needed for a long term production.

Throughout development of the PVD process, many equipment modifications of both vacuum systems were made, including $r f$ vapor source stabilization, planetary fixtures, shielding, and valve actuation, to assure more consistent product purity, appearance, and material repeatability, Many sets of deposited samples were tested and characterized to establish their total thickness, thickness uniformity, electrical resistivity, adhesion, spectral and total reflectance, deposit defects, and deposit material composition. Throughout this coating development, the rf induction vapor source systen and the electron beam gun vapor source system utilized various equipment items to assist in providing controlled process procedures to obtain repeatable coating materíal properties. A quadropole mass spectrometer used for residual gas analysis of the deposition chamber provided information on the gaseous species evolved during thermal treatment of the polyimide substrates and during deposition to determine their effects on the resulting deposit. The in-process high vacuum thermal treatment utilized quartz heaters to provide repeatable substrate bake-out to minimize water and air contamination. The use of process thickness and deposition rate monitors and controllers provided the high reliability needed for thickness repeatability from part-to-part and from deposition run-to-deposition run. The rotational planetary system was designed to provide interchangeability of various size substrates with minimal operator time and fixture exchange.

This development has provided Bendix with a significant vacuum processing and deposit characterization background that is expandable to new thin film metallization applications where thick, uniform, and repeatable metal coatings are required.

\section{RF Induction Vapor Source}

A physical vapor deposition process with an $r$ induction vapor source was developed to deposit $11.2 \mu \mathrm{m}$ aluminum-0.12 weight percent copper allay films on polyimide laminate substrates. The total thickness values can be repeated within $a \pm 0.5 \mu m$ range with a 90 percent yield. The average thickness uniformity (standard deviation/average thickness) of these deposits was 1.2 percent, as determined by beta backscatter measurements for 100 substrates. The aluminum-0.3 weight percent copper vapor charge resulted in a 
copper content in the deposit of approximately 0.12 weight percent. Metallurgical and chemical analyses show that the copper was not preferentially distributed in the deposit, as related to the deposit-laminate or outer surface interfaces, but was constant throughout the deposit. The maximum laminated substrate temperatures for a $5 \mathrm{~nm} / \mathrm{s}$ and $10 \mathrm{~nm} / \mathrm{s}$ deposition rate were $190^{\circ} \mathrm{C}$ and $225^{\circ} \mathrm{C}$, respectively. The resistivity of the aluminum- 0.12 weight percent copper deposits is $3 \mu \Omega-\mathrm{cm}$ or less and is stable from one deposition run to another. Also, the resistivity was not related to the geometry of the non-planar substrate. The $11.2 \mu$ n thick aluminum-0.12 weight percent copper film's density was greater than 99 percent of theoretical, and its adhesion to the polyimide exceeds that required for post-deposition operations and handling. Physical vapor deposited aluminum-0.12 weight percent copper films were provided for beta backscatter thickness standards. These standards were instrumental in achieving the reported uniformity values and in determining the beta backscatter uncertainty of the developed measurement. 3,4

\section{Electron Beam Gun Vapor Source}

The major Eechnical goal for this PVD coating development was to use pure aluminum as the coating material. Consequently, the aluminum-0.12 weight percent copper coating material was an alternate material. As mentioned previously, the electron beam gun vapor source system was purchased prinarily for depositing pure aluminum and was used extensively for this purpose. As a result of these activities, a highly reliable aluminum deposition capability, process, and deposit characterization were achieved.

A process was developed for the vacuum deposition by electron-beam evaporation of high quality aluminum films 10 ph thick on non-planar three-layer laminated substrates consisting of Kapton/modified acrylic thermoplastic/aluminum. Thermogravimetric analysis and mass spectrometry of the substrate materials and in-process residual gas analysis were used to determine the outgassing characteristics of the substrate laminate and to aid in the development of suitable thermal processing. The laminated substrates required bake-outs both at atmosphere and in high vacuum prior to deposition to permit evaporation at a pressure of $0.1 \mathrm{mPa}$.

Required film properties were a thickness uniformity across the entire non-planar part of less than 2 percent, a resistivity near that of bulk pure aluminum, a smooth and shiny film surface, and adequate adhesion. A beta backscatter technique was used for film thickness determination; uniformity in the 1 percent range was attained. An integrating sphere reflectometer was used for surface appearance measurements; the process that was developed yielded films whose surfaces had a total reflectance of 90 percent, with 80 to 90 percent of the reflected light specularly reflected. 
Film resistivity was determined both with a four-point probe and with photoprocessed resistor patterns; the evolved deposition process resulted in an aluminum film resistivity of $2.8 \mu \Omega-\mathrm{cm}$ where bulk pure aluminum is $2.71 \mu \Omega-\mathrm{cm}$. Film adhesion was sufficient to withstand adhesive tape snap-pull testing. X-ray pole figure analysis showed that the deposited pure aluminum films exhibited a strong (111) preferred orientation.

Pattern Deposition

The feasibility of pattern deposition on Rapton also was investigated. Initially, bimetallic masks and precision pattern deposition by direct contact of these masks on flat Kapton substrates was investigated. The high vacuum system with an electron-beam gun vapor source was used to make 10-pm-thick deposits of pure aluminum at a rate of $5 \mathrm{~nm} / \mathrm{s}$. Prior to and following deposition, the masks were inspected and measurements taken off its pattern. These values were compared to similar measurements obtained on the deposited patterns.

Deposits were made in two different locations within the vacuum system. The first was a two-axis rotation, $60^{\circ}$ tilt from the vapor source axis; the second setup involved rotating the planet with the mask and substrate orientated normal to the vapor source axis. With this second type of rotation, the number of planets is limited for deposition. For comparison, the single axis rotation limits one to a single planet, while the $60^{\circ}$, two-axis rotation provides for three planets to be used.

In general, the single-axis rotation provided a better defined pattern with less edge taper, providing the mask was in intimate contact with the substrates. The $60^{\circ}$, two-axis rotation patterns had a slight edge taper when the mask was in intimate contact with the substrate, and larger edge tapers when the mask was not in intimate contact with the substrate. If the measured anount of this edge taper is acceptable, this fixturing has appeal because three parts can be plated simultaneously and reproducibly.

Results indicated that this pattern deposition process is feasible, but further development will be required to establish this capability as a manufacturing process.

\section{ACCOMPLISHMENTS}

During this study, four coating techniques were evaluated to provide uniform metal coatings on non-metallic laminated substrates. The methods were ion plating, chemical vapor deposition, electroless plating, and physical vapor deposition. Results showed physical vapor deposition to be the most promising technique 
for depositing uniform, thick metal coatings, and further development concentrated on establishing required vacuum metallization equipment and processes. Development of the physical vapor deposition technique yielded two processes with independent characterization of their equipment and deposits properties.

The first process utilized an $r f$ induction source and resulted in an aluminum-0.12 weight percent copper alloy deposit. Thickness uniformity for various non-planar substrates was less than 2 per* cent and thíckness repeatability was greater than 90 percent. Room temperature electrical resistivity was $3.0 \mu \Omega-\mathrm{cm}$ or less. Total and specular reflectance were 84 and 87 percent, respectively. Density was within 1 percent of bulk. The aluminum-0.12 weight percent copper film had a preferred (111) crystal orientation and grain size of 0.5 to $1.0 \mathrm{\mu m}$. The copper was uniformly distributed throughout the deposit, as deternined by electron microprobe analysis. Adhesion of the deposited films to the Kapton exceeded that required for post deposition operations and handling. This deposition system was a development unit. Because it is a manually operated system, it is not attractive for a production-oriented environment.

The second physical vapor deposition process used an electron beam gun vapor source. Pure aluminum was the primary material deposited from this sytem. Thickness uniformity was less than 2 percent, and repeatability was greater than 90 percent. Electrical resistivity of the aluminum deposits was $2.85 \mu \Omega-\mathrm{cm}$ or less with a total and specular reflectance of 90 and 80 to 90 percent, respectively. Densicy exceeded 99 percent of the theoretical bulk value. The pure aluminum films had a preferred crystal orientation of (111) with a grain size range of 0.5 to $1.0 \mu m$. The adhesion of the deposited films exceeded all requirements in post-deposition operations and handling. This physical vapor deposition system is a semi-automatically controlled system which provides the repeatability and reliabilicy necessary in a production-oriented environment.

Precision pattern deposition from an electron beam gun source was evaluated. Bimetallic masks were used to generate precision patterns on flat Kapton substrates. Results indicated direct deposition of precision patterns are possible if the masks are held in intimate contact with the Kapton substrate. Special handling and storage would be required to provide consistent patterns, because the bimetallic masks are easy to damage.

\section{FUTURE WORK}

Future development is required to finalize details associated with increasing the overall yield and to provide a general manufacturing capability for the electron beam gun vacuum deposition 
system. Current requirements will require costing different and various sjzed non-planar and planar polyimide substrates. Development time is required to modify fixtures and to optimize set points for process variables for each size and configuration of these new substrates. Also, the evaluation and development of an alternate vapor material and source will be required to increase the vacuum system's capability to coat these new configurations.

Preliminary surface analysis of the polyimide has shown excessive chemical contaminants, which will require an improved substrate cleaning process. However, repeated problems with other defects in the deposits, such as particulates and hydrocarbon contamination on the laminate substrate surface, require continued analysis to identify their source and to determine better handling procedures or in-vacuum cleaning techniques to minimize their content: The evaluation and development of precision pattern deposition will be continued with major emphasis on precision photo pattern masks being applied to non-planar substrates. 


\section{REFERENCES}

1F. A. Clay, Chemical Vapor Deposition of Aluminum (Final Report). Bendix Kansas City: BDX-613-866 (Rev.), August, 1973 (Available from NTIS).

${ }^{2} \mathrm{C}$. J. Stimetz, Plating on Polyimide (Topical Report). Bendix Kansas City: BDX-613-1177 (Rev.), August, 1974 (Available from NTIS).

${ }^{3} \mathrm{R}$. V. Heckman, Beta Backscatter Measurements of Aluminum Coatings on Mylar Substrates (Topical Report). Bendix Kansas City: BDX-613-1028 (Rev.), September, 1974 (Available from NTIS).

4R. J. Russell, Development of Plating. Thickness Standards for Physical Vapor Deposition of Aluminum on Kapton (Hilestone Report). Bendix Kansas City: BDX-613-1634, 0ctober, 1977 (Available from NTIS). 


\section{DISTRIBUTION}

R. Bulcock, DOE- $\mathrm{KCAO}$

V. C. Vespe, DOE-ALO

B. Ferrel1, LASL

J. A. Freed, LASL.

T. Maier, LASL

W. H. Meyers, LASL

S. J. Buginas, LLL

F. J. Huegel, LLL

5. Palermo, LLL

J. . Strond, LLL

R. C. Weíngart, LLL

D. F. Wright, LLL

H. M. Brinkmeier, Monsanto

N. Brown, SLA

D. M. Mattox, SLA

D. Schuster, SLL

J. E. Long, D/531, $1 \mathrm{A4} 6$

H. T. Barnes, D/554, BD50

L. Stratton, D/554, $2 C 44$

C. R. Beary, D/755, 1A42

R. P. Frohmberg, $D / 800,2 A 39$

F. A. Spies, D $/ 800,2 \mathrm{A39}$

J. W. Chesney, D/814, $2 \mathrm{C} 43$

W. H. Deterding, $D / 814,2 \mathrm{C} 43$

G. J. Hale, D/814, $2 \mathrm{C43}$

B. Z. Rosenblum, D/814, 2C43

P. E. Smith, D/814, 2C43

D. L. Stoltz, D/814, 2C43

J. C. Culver, D/842, 2D39

T. A. Wiley, D/842, MD40

R. E. Kessler, D/865, 2C40 


\section{BDX-613-2062 (Rev.)}

COATING LAMINATED SUBSTRATES, G. J.. Hale, Final, January 1979.

This report, covering a 4-year project, summarizes the feasibility and development results for coating uniform 6.3 to $12,7 \mu$ metal films on flat and non-planar Mylar or Kapton laminated substrates. Four coating techniques (ion plating of aluminum, chemical vapor deposition of aluminum, electroless plating of copper and nickel, and physical vapor deposition of aluminum and aluminum-0.12 weight percent copper) were evaluated. Based on the capability of each 1 process and the resulting properties and structure of these coatings with respect to the

\section{SPECIAL PROJECTS: Metal Films}

COATING LAMINATED SUBSTRATES, G. J. Hale, Final, BDX-613-2062 (Rev.), January 1979.

This report, covering a 4-year project, summar- 1 izes the feasibility and development results for 1 coating uniform 6.3 to $12.7 \mu \mathrm{m}$ metal films on flat and non-planar Mylar or Kapton laminated substrates. Four coating techniques (ion plating of aluminum, chemical vapor deposition of aluminum, electroless plating of copper and nickel, and physical vapor deposition of aluminum and aluminum-0.12 weight percent copper) were evaluated. Based on the capability of each process and the resulting properties and structure of these coatings with respect to the

COATING LAMINATED SUBSTRATES, G. J. Hale, Final, BDX-613-2062 (Rev.), January 1979.

This report, covering a 4-year project, summarizes the feasibility and development results for I coating uniform 6.3 to $12.7 \mu$ metal films on flat and non-planar Mylar or Kapton laminated substrates. Four coating techniques (ion plating of aluminum, chemical vapor deposition of aluminum, electroless plating of copper and nickeI, and physical vapor deposition of aluminum and aluminum-0.12 weight percent copper) were evaluated. Based on the capability of each process and the resulting properties and structure of these coatings with respect to the 
requirements, physical vapor deposition was selected. for further development. Processes' were developed for aluminum-0.12. weight percent copper.alloy from an rf induction vapor source and for depositing pure aluminum from an electron beam gun vapor source. In addition, precision pattern deposition of aluminum from an electron beam gun vapor source was. demonstrated for flat Kapton

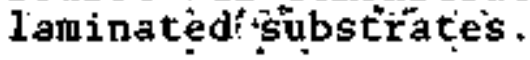

$$
\because \therefore i j
$$

requirements,. physical vapor deposition was. selected: for further: development. Processes. were developed for aluminum-0.12 weight percent. copper alloy from an $r f$ induction vapor. source and for depositing pure aluminum from an electron beam gun vapor source, In addition, precision patcern deposition of aluminum from an electron beam gun vapor source was demonstrated for flat Kapton laminated; substrates.

requirements, physical.ivapor deposition was selected. for further: development. Processes were developed for aluminum-0.12: weight percent. copper alloy. from an $r f$. induction vapor source and for depositing. pure aluminum. from an electron, beam gun vapor-source. In addition, precision pattern deposition of aluminum from an electron beam. gun vapor source was-demonstrated for flat Rapton layninated substrates. 